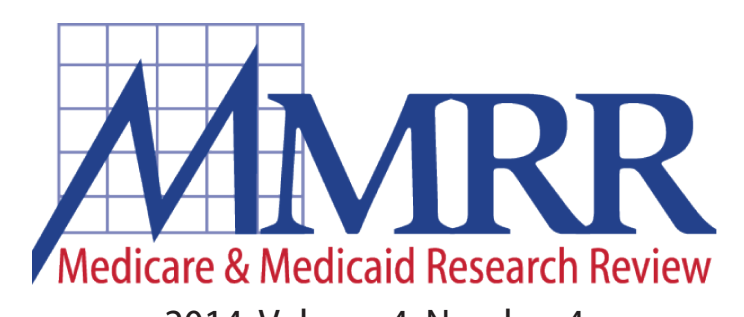

2014: Volume 4, Number 4

A publication of the Centers for Medicare \& Medicaid Services, Office of Information Products \& Data Analytics

\title{
Insurance Coverage \& Whither Thou Goest for Health Information in 2012
}

\author{
Loren Saulsberry, ${ }^{1}$ Mary Price, ${ }^{2}$ and John $\mathrm{Hsu}^{2}$ \\ ${ }^{1}$ Harvard University_Cambridge, Massachusetts \\ ${ }^{2}$ Massachusetts General Hospital-Mongan Institute for Health Policy
}

Objective: Examine use of the Internet (eHealth) and mobile health (mHealth) technologies by privately insured, publicly insured (Medicare/ Medicaid), or uninsured U.S. adults in 2012.

Data Source: Pew Charitable Trust telephone interviews of a nationally representative, random sample of 3,014 adult U.S. residents, age 18+.

Methods: Estimate health information seeking behavior overall and by segment (i.e., insurance type), then, adjust estimates for individual traits, clinical need, and technology access using logistic regression.

Results: Most respondents prefer offline to online (Internet) health information sources; over half across all segments use the Internet. More respondents communicate with providers offline compared with online. Most self-reported Internet users use online tools for health information, with privately insured respondents more likely to use new technologies. Unadjusted use rates differ across segments. Medicaid beneficiaries are more likely than the privately insured to share health information online, and Medicare beneficiaries are more likely than the privately insured to text with health professionals. After adjustment, these differences were minimal (e.g., Medicare beneficiaries had odds similar to the privately insured of online physician consultations), or the direction of the association reversed (e.g., Medicaid beneficiaries had greater odds than the privately insured of online physician consultations versus lower odds before adjustment).

Discussion: Few adults report eHealth or mHealth use in 2012. Use levels appear unevenly distributed across insurance types, which could be mostly attributed to differences in individual traits and/or need. As out-of-pocket costs of medical care increases, consumers may increasingly turn to these generally free electronic health tools.

Keywords: Medicare, Medicaid, private insurance, eHealth, mHealth, health insurance, technology, surveys, interviews

ISSN: 2159-0354

doi: http://dx.doi.org/10.5600/mmrr.004.04.b01 
Medicare \& Medicaid Research Review 2014: Volume 4, Number 4

\section{Mission Statement}

Medicare \& Medicaid Research Review is a peerreviewed, online journal reporting data and research that informs current and future directions of the Medicare, Medicaid, and Children's Health Insurance programs. The journal seeks to examine and evaluate health care coverage, quality and access to care for beneficiaries, and payment for health services.

\section{http://www.cms.gov/MMRR/}

\section{Centers for Medicare \& Medicaid Services Marilyn Tavenner Administrator}

Editor-in-Chief

David M. Bott, Ph.D.

The complete list of Editorial Staff and Editorial Board members

may be found on the MMRR Web site (click link):

$$
\underline{\text { MMRR Editorial Staff Page }}
$$

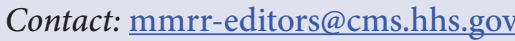

Published by the Centers for Medicare \& Medicaid Services.

All material in the Medicare \& Medicaid Research Review is in the public domain and may be duplicated without permission. Citation to source is requested.

\section{Introduction}

Americans increasingly are using the Internet and mobile devices to address health needs. Electronic health (eHealth) is the use of electronic technologies to access and communicate health information that facilitates health care management. ${ }^{1}$ Numerous eHealth tools are Internet accessible, and mobile health (mHealth) technologies, a subcategory of eHealth, are available through mobile devices (e.g. smartphones).

Earlier studies suggest that these technologies increase access to medical information (Fox \& Duggan, 2013a); facilitate self-tracking of weight, diet, or exercise (Fox \& Duggan, 2013b); and enable health information sharing (White, Tatonetti, Shah, Altman, \& Horvitz, 2011). The Internet enables users to connect to a knowledgeable community and facilitates patient-provider communication (Beckjord et al., 2007; Ginsberg, 2011). Some reports suggest that eHealth is revolutionizing the exchange of health information and the delivery of health care services (Fox \& Jones, 2009).

The Department of Health and Human Services (HHS) and the Centers for Medicare \& Medicaid Services (CMS) are implementing programs to capitalize on eHealth tools to improve health care delivery. For example, HHS has established several programs to nationally expand health information technology (health IT) infrastructure and to support consumer use of eHealth tools (ONC, 2013a). CMS has spent billions to encourage the use of electronic health records (EHR) and electronic drug prescriptions

\footnotetext{
${ }^{1}$ Our definition of eHealth is derived from both the U.S. Department of Health and Human Services (http://www.health.gov/ communication/ehealth/) and the Centers for Medicare \& Medicaid Services (http://www.cms.gov/eHealth/about.html)
} 
(CMS, 2013). Both agencies are collaborating to develop meaningful use criteria to establish standards for eHealth use (ONC, 2013b).

While eHealth is intuitively appealing, little empirical data demonstrates pervasive, consistent eHealth use. The Pew Research Center finds that contrary to perceptions of universal use, 19\% of U.S. adults do not use the Internet while 15\% do not own a cell phone (Fox \& Duggan, 2013a). Additionally, only $9 \%$ of American adults have health related software applications ("apps") on their phone (Fox, 2011).

Great enthusiasm surrounds eHealth, but some research suggests that new technologies could exacerbate existing health care disparities creating a "digital divide" (i.e., increasing differences in technology-based care between advantaged and disadvantaged groups). Knowledge, access, and willingness could be contributing sources of inequities in health technology use, but the full scope of potential factors contributing to use differences has not been identified. Pew finds that women, individuals with higher levels of education and income, non-Hispanic Whites, and younger adults are more likely to use technology and obtain health information online (Fox, 2011; Fox \& Duggan, 2013a). Hsu et al. (2005) demonstrate disparities in eHealth use between $\mathrm{racial} / \mathrm{ethnic}$ groups and by socioeconomic status (SES).

Prior research indicates that insurance matters when assessing health disparities and contemplating policy solutions in the U.S. (KFF, 2007; KFF, 2008; Mead, Cartwright-Smith, Jones, Ramos, \& Siegel, 2008; KCMU, 2013). For example, Medicaid beneficiaries often have a greater illness burden or less education than the privately insured. Since insurance status frequently distinguishes vulnerable/disadvantaged patients, it could be an informative indicator for identifying populations with differential eHealth use. Feasible policy solutions may need to vary by insurance type, where separate. Tailored solutions are developed for the relevant stakeholders and population needs within the commercial insurance, Medicare, Medicaid, and uninsured groups. Presently, scarce information exists on how individuals of varying insurance types use eHealth, making it difficult to evaluate utilization by individuals with varying health care coverage.

In this report, we address a gap in the literature on eHealth by examining U.S. adult use of the Internet and mHealth across insurance types. In short, we compare use by insurance status because we wish to answer the question of whether insurance type as a group level, categorical indicator that affects patient interaction with the health care system, would be associated with technology use. Data from impartial sources, like the Pew Research Center, on the uses of eHealth are essential for policy makers seeking to track use and need. The Pew survey data is rich across a range of dimensions that allow for identifying factors that might contribute to differences in eHealth use. These associated factors could have distinct implications for innovators and policy makers (Cohen \& Adams, 2011; Goel et al., 2011; Hsu et al., 2005). Since policy interventions often target populations according to insurance coverage, this study also contributes to the literature in assessing whether facilitating technology use primarily on the basis of insurance type could help close the "digital divide."

\section{Methods}

The Pew Charitable Trusts interviewed a nationally representative random sample of 3,014 adult U.S. residents, age 18+. Princeton Survey Research Associates, a survey firm, conducted the interviews between August 7 to September 6 in 2012 through 
landline and cell phone interviews. The survey firm identified the subjects through random digit dialing (i.e., random generation of the last two digits of telephone numbers). The publicly available dataset includes sampling weights based on data for adults living in households containing a telephone in the Census Bureau's Current Population Survey (March 1999). Here we present only weighted survey responses. The survey conducted in 2012 is part of a series of fielded health related surveys that Pew has conducted every two years since 2006.

We categorized subjects into four groups according to their self-reported, primary source of health insurance in 2012: 1) Medicare; 2) Medicaid; 3) private insurance; and 4) no health insurance. In the Pew survey, subjects reported coverage through Medicare, Medicaid, private group insurance, private individual insurance, and/or other. Other included people reporting some insurance without specifying the source (i.e., military/veterans coverage). When subjects reported multiple sources of health insurance without indicating the primary source, we imposed the following hierarchy in decreasing order of priority: Medicare $>$ Medicaid $>$ private group insurance $>$ private individual insurance $>$ other $>$ none. For example, we classified subjects reporting Medicare and Medicaid coverage (i.e., dual eligibles) as having Medicare insurance. The private health insurance group used in our analysis included subjects reporting private insurance of any type.

The interviews gathered information on individual characteristics (e.g., sociodemographic and economic traits, health status, caretaker responsibilities, and technology access). All individual covariates used reference specific Pew survey questions and their responses (details available upon request). We included age as a continuous variable. Specific survey questions distinguished Internet users from non-Internet users as well as cell phone users from non-cell phone users; these questions provided a filter in the survey for subsequent questions asked of only Internet users, only cell phone users, or combination users. We classified any subject indicating prior use of the Internet within the Pew survey as an Internet user, which provides a conservative estimate of Internet accessibility and use. The survey asked questions on text messaging behavior only among respondents who had previously indicated that they were cell phone users that sent/received text messages. Interview questions, response categories, and response data are all available on the Pew Web site (Pew Research Center, 2012).

In all models, we dichotomized educational attainment, categorizing subjects as having any college degree or no degree. We were interested in the role that clinical need due to poor health might have on outcomes, thus in the main analyses, we dichotomized the self-reported health status variable (originally on a 5-point Likert scale) into "Fair/Poor health vs. Not being in Fair/Poor health." For the subjects who reported "Don't Know" or who refused to answer, we coded them as "Not being in Fair/Poor Health." We used similar definitions to dichotomize variables representing respondents' having a chronic disease or any recent emergency health event. ${ }^{2}$ We defined informal caregivers as anyone who reported providing unpaid care to an adult or child.

To determine the categories of Federal Poverty Level (FPL), we followed the Health and Human Services 2012 Poverty Guidelines, assigning income as the mid-point of the category. If a respondent indicated they had children, we

\footnotetext{
${ }^{2}$ Logistic regression analyses were performed according to

dichotomized variables described here. The same analyses with identical dichotomized variables were performed with "Don't Know" and "Refused" responses coded as missing (data not shown here); this coding change did not significantly impact the results.
} 
assumed two children lived in the household. We limited the number of adults per household to six and determined household size from the sum of the children and adults in that home. Based on income and household size, we determined the percent of federal poverty and created categorical poverty level variables.

Using logistic regression, we examined the association between insurance type and several measures of information seeking behavior to identify potential sources of variation in behavior among these populations. As a part of the regression modeling, we conducted both "unadjusted" and "adjusted" regression analyses. The "unadjusted" models only contain indicators for health insurance type. The "adjusted" models contain these insurance indicators plus the individual characteristics listed in Exhibit 1.

\section{Results}

\section{Survey Respondents}

Among the 3,014 survey respondents, 52\% had private health insurance; $21 \%$ had Medicare (5\% of all subjects were dual eligible for Medicare and Medicaid); 9\% had Medicaid; and 18\%

Exhibit 1. Survey Respondent Characteristics (Weighted)

\begin{tabular}{lcccc}
\hline & Private Insurance & Medicare & Medicaid & Uninsured \\
\hline Unweighted sample size & 1462 & 938 & 201 & 413 \\
Age (mean \& standard deviation) & 43.0 & 68.7 & 39.7 & 37.5 \\
& $(15.2)$ & $(14.4)$ & $(14.3)$ & $(15.5)$ \\
Female \% & 51.3 & 55.7 & 59.5 & 41.0 \\
College degree \% & 53.5 & 28.7 & 17.2 & 18.0 \\
Hispanic ethnicity \% & 9.5 & 7.4 & 21.0 & 27.7 \\
White race \% & 77.5 & 79.8 & 56.9 & 63.1 \\
Black race \% & 11.0 & 12.7 & 19.6 & 16.4 \\
Other race \% & 11.5 & 7.5 & 23.5 & 20.6 \\
Fair/Poor health \% & 11.3 & 35.0 & 33.0 & 21.5 \\
Any chronic disease \% & 35.3 & 77.5 & 49.7 & 29.5 \\
Any emergency or health shock \% & 24.5 & 22.1 & 54.5 & 30.6 \\
Caregiver activity \% & 43.0 & 31.7 & 46.1 & 31.0 \\
Northeast residence\% & 22.7 & 14.7 & 21.9 & 12.8 \\
Midwest \% & 22.3 & 25.8 & 23.5 & 16.1 \\
South \% & 21.5 & 40.3 & 27.2 & 43.5 \\
West \% & 33.5 & 19.2 & 27.5 & 27.6 \\
Income $\leq 100 \%$ FPL \% & 6.9 & 18.2 & 56.5 & 39.9 \\
$>100 \%-199 \%$ FPL \% & 13.1 & 16.0 & 25.0 & 27.7 \\
$\geq 200 \%$ FPL \% & 66.7 & 38.8 & 4.5 & 18.1 \\
Unknown FPL \% & 13.3 & 27.0 & 14.0 & 14.2 \\
Internet user \% & 93.4 & 56.1 & 72.1 & 78.9 \\
\hline OOF Re. & & & \\
\hline
\end{tabular}

NOTES: Respondents in the Pew Research Center's 2012 Health Survey (Internet \& American Life Project) telephone interviews, which were conducted in English and Spanish by landline $(1,808)$ and cell phone $(1,206$, including 624 without a landline phone). Means and percents weighted using information from the 1999 CPS. The margin of sampling error for the complete set of weighted data is \pm 2.4 percentage points. For all characteristics, there were statistically significant differences $(\mathrm{p}<0.05)$ across the insurance types.

SOURCE: Pew Research Center's 2012 Health Survey (Internet \& American Life Project) telephone interviews. 
were uninsured (Exhibit 1). Subjects differed considerably by insurance type with respect to socio-demographic, economic, and clinical characteristics. The percentage of private insurance beneficiaries with college degrees (53.5\%) was higher than the college-educated on Medicaid (17.2\%) or who were uninsured (18\%). More than half of all survey respondents were self-reported Internet users: $93 \%$ of privately insured adults and $56 \%$ of Medicare beneficiaries reported Internet use.

\section{Communication with health care providers occurs primarily offline (WITHOUT the Internet)}

Professional Advice (ALL RESPON-

DENTS): Thinking about the LAST time you had a serious health issue or experienced any significant change in your physical health... Did you get information, care or support from a doctor or other health care professional?

All respondents were asked to indicate whether they sought professional advice (i.e., yes or no) and through what medium advice was sought (i.e., online, offline, or both online and offline). "Don't know" and "Refused" options were available. Any respondents who were non-Internet users responding yes to this question were coded as yes, offline responses. Substantially, more respondents reported seeking care through in-person visits or telephone

\section{Exhibit 2. Percent Seeking Health Information from a Doctor, Any Online Efforts vs. Offline Only, by Insurance} Type (unadjusted percent)

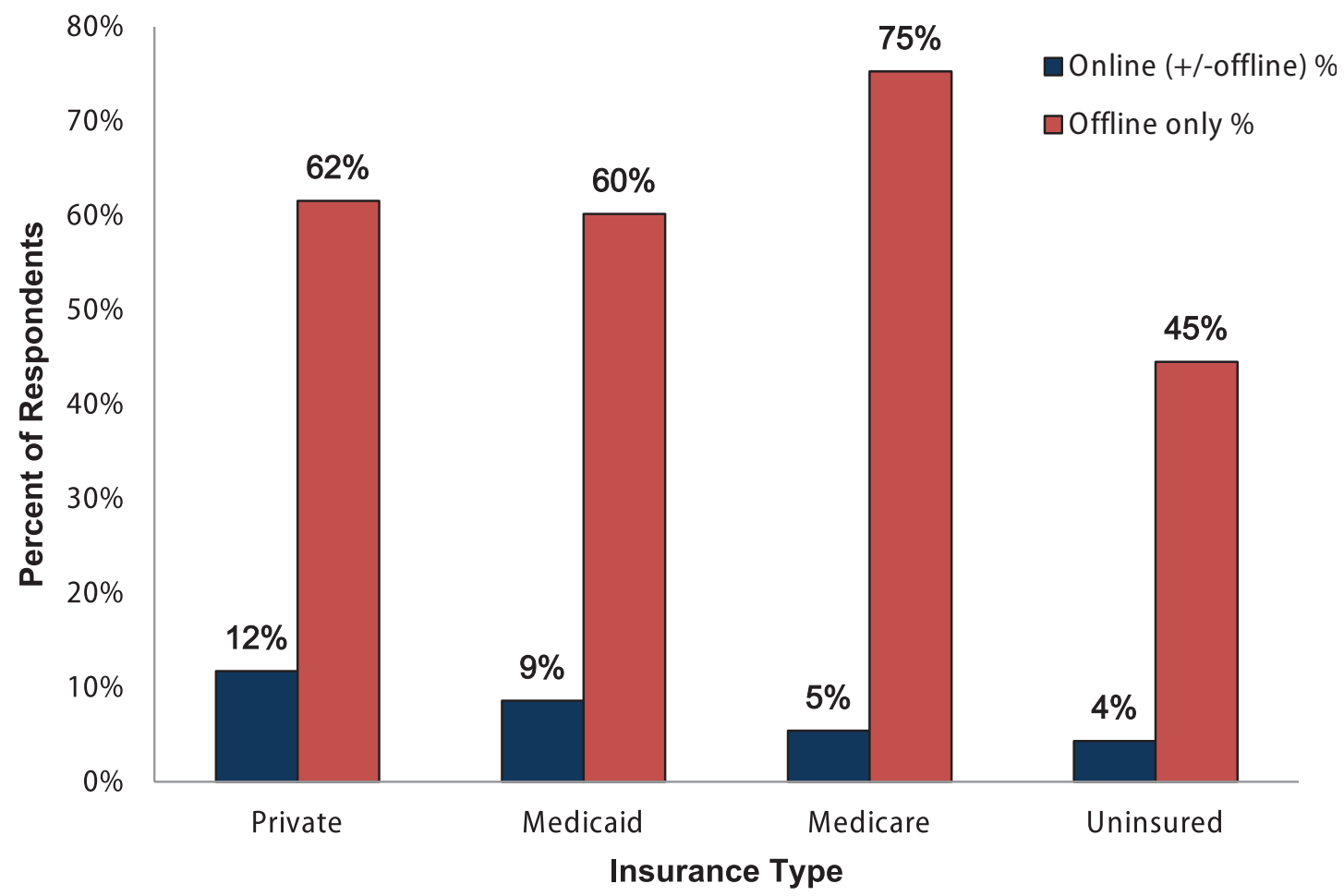

NOTES: Percents represent unadjusted values, weighted, using information from the 1999 CPS. Percents do not total 100 as all responses in Other were excluded from Exhibit 2. Other included “No, did not use this source," “Don't know," and “Refused.” Across all measures, <3\% (weighted) responded "Don't know” or "Refused.” Denominator consists of all respondents including subjects reporting having each type of insurance. When subjects report having both Medicare and Medicaid (i.e., dually eligible), we classified them as having Medicare. SOURCE: Pew Research Center's 2012 Health Survey (Internet \& American Life Project) telephone interviews. 
calls than through online communication like email or Web messaging (Exhibit 2). Use of online consultations with a doctor varied across the insurance groups in unadjusted analysis (Exhibit 2), ranging from $12 \%$ of the privately insured to $4 \%$ of uninsured adults.

After adjustment (Exhibit 3), Medicare beneficiaries had similar odds of seeking online consultations with doctors as privately insured adults (unadjusted $\mathrm{OR}=0.43,95 \% \mathrm{CI}$ : $0.37-0.50$; adjusted $\mathrm{OR}=0.97$, 95\% CI: 0.80-1.17). After adjustment, Medicaid beneficiaries had greater odds (adjusted OR=1.45, 95\% CI: 1.17-1.81) of seeking online physician consultations than privately insured adults (vs. having lower odds before adjustment, unadjusted $\mathrm{OR}=0.71,95 \%$ CI: 0.59-0.85).

\section{The Internet provides a wide variety of valuable health information}
Internet Health Information Searches (ONLY INTERNET USERS): Specifi- cally, in the last 12 months, have you looked online for information about any of the following items: specific disease or medical prob- lem; treatment or procedure; health insurance; pregnancy or childbirth; food safety or recalls; drug safety or recalls; medical test results; weight

Exhibit 3. Seeking Information Online from a Doctor (multivariate logistic model)

\begin{tabular}{|c|c|c|c|}
\hline & OR & $95 \%$ & CI \\
\hline Medicaid (vs. Private) & 1.45 & 1.17 & 1.81 \\
\hline Medicare (vs. Private) & 0.97 & 0.80 & 1.17 \\
\hline None (vs. Private) & 0.67 & 0.55 & 0.82 \\
\hline Age & 0.98 & 0.97 & 0.98 \\
\hline Female (vs. Male) & 1.11 & 0.99 & 1.23 \\
\hline College Degree (vs. No College Degree) & 2.22 & 1.97 & 2.50 \\
\hline Hispanic (vs. non-Hispanic) & 0.77 & 0.64 & 0.93 \\
\hline Black (vs. White) & 1.26 & 1.07 & 1.49 \\
\hline Other (vs. White) & 1.51 & 1.29 & 1.76 \\
\hline Fair/Poor health (vs. Not) & 0.80 & 0.68 & 0.94 \\
\hline Any Chronic Dx (vs. None) & 1.64 & 1.45 & 1.86 \\
\hline Any Emergency or Health Shock (vs. None) & 1.64 & 1.45 & 1.85 \\
\hline Active Caregiver (vs. Not a Caregiver) & 2.23 & 2.00 & 2.49 \\
\hline Midwest (vs. Northeast) & 1.57 & 1.32 & 1.88 \\
\hline South (vs. Northeast) & 1.58 & 1.34 & 1.86 \\
\hline West (vs. Northeast) & 2.12 & 1.78 & 2.52 \\
\hline$>100 \%-199 \%$ FPL (vs. $\leq 100 \%$ FPL) & 1.75 & 1.38 & 2.22 \\
\hline$\geq 200 \%$ FPL (vs. $\leq 100 \%$ FPL) & 4.01 & 3.22 & 5.00 \\
\hline Unknown FPL (vs. $\leq 100 \%$ FPL) & 2.53 & 1.98 & 3.24 \\
\hline
\end{tabular}


control; reduction of my health care costs; caring for an aging relative or friend; a drug that I saw advertised; or any other health issue.

Only self-reported Internet users were asked to respond yes, no, don't know, or refused for each of the items listed in the above question. Over $50 \%$ of Internet users sought health information online. The unadjusted percent that went online for health information for any reason varied by insurance type with $77-78 \%$ of Medicaid and private insurance beneficiaries reporting this behavior while $59 \%$ of the uninsured behaved similarly (Exhibit 4).
After adjustment, Medicare beneficiaries had similar odds of conducting online health information searches as did privately insured respondents (unadjusted $\mathrm{OR}=0.49,95 \%$ CI: $0.44-0.54$; adjusted OR=0.90, 95\% CI: 0.791.02, Exhibit 5).

Medicaid beneficiaries had odds of this behavior comparable to privately insured respondents before and after adjustment (Exhibit 5). Females ( $\mathrm{OR}=2.03$ females vs. males, 95\% CI: 1.87-2.20, Exhibit 5) and individuals providing uncompensated care for another person ( $\mathrm{OR}=2.67$ for active caregivers vs. non-caregivers, 95\% CI: 2.45-2.91, Exhibit 6) were more likely to look online for health information.

\section{Exhibit 4. Percent Seeking Health Information Online for Any Reason, by Insurance Type (Unadjusted Percent)}

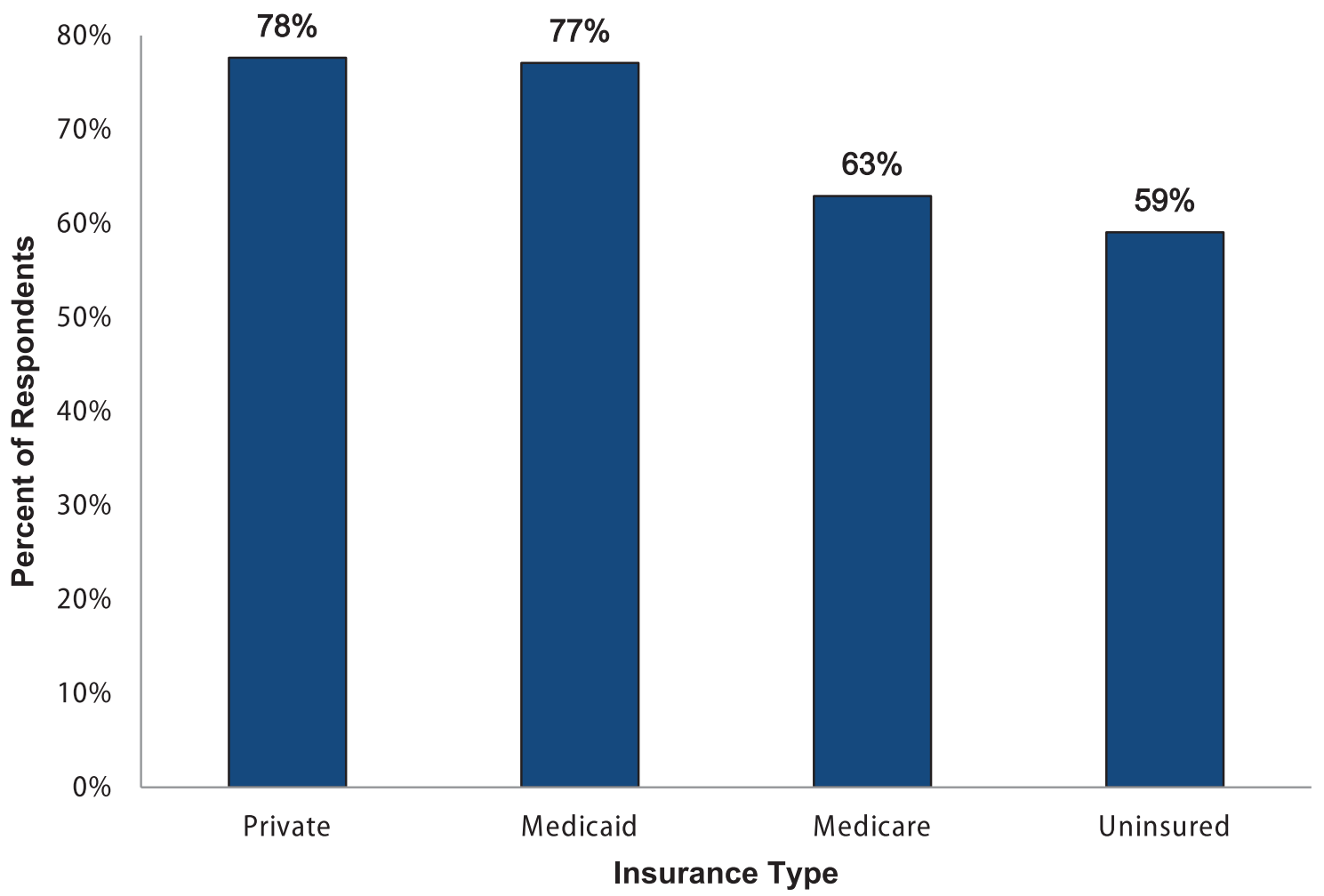

NOTES: Percents represent unadjusted values of online use for any of the listed reasons in the survey, weighted, using information from the 1999 CPS. Across all measures, <1\% responded “Don't know” or “Refused.” Denominator consists of all subjects reporting having insurance of each type AND who reported being Internet users. When subjects report having both Medicare and Medicaid (i.e., dually eligible), we classified them as having Medicare.

SOURCE: Pew Research Center's 2012 Health Survey (Internet \& American Life Project) telephone interviews. 
Exhibit 5. Seeking Health Information Online for Any Reason (Multivariate Logistic Model)

\begin{tabular}{llll}
\hline & OR & 95\% & CI \\
\hline Medicaid (vs. Private) & 1.09 & 0.92 & 1.30 \\
Medicare (vs. Private) & 0.90 & 0.79 & 1.02 \\
None (vs. Private) & $\mathbf{0 . 6 0}$ & 0.54 & 0.68 \\
Age & $\mathbf{0 . 9 8}$ & 0.97 & 0.98 \\
Female (vs. Male) & $\mathbf{2 . 0 3}$ & 1.87 & 2.20 \\
College Degree (vs. No College Degree) & $\mathbf{1 . 9 4}$ & 1.78 & 2.12 \\
Hispanic (vs. non-Hispanic) & $\mathbf{0 . 8 0}$ & 0.70 & 0.90 \\
Black (vs. White) & 0.96 & 0.85 & 1.09 \\
Other (vs. White) & 1.13 & 1.00 & 1.28 \\
Fair/Poor health (vs. Not) & 1.09 & 0.96 & 1.23 \\
Any Chronic Dx (vs. None) & $\mathbf{1 . 2 4}$ & 1.13 & 1.36 \\
Any Emergency or Health Shock (vs. None) & $\mathbf{1 . 9 1}$ & 1.73 & 2.11 \\
Active Caregiver (vs. Not a Caregiver) & 2.67 & 2.45 & 2.91 \\
Midwest (vs. Northeast) & $\mathbf{0 . 6 9}$ & 0.61 & 0.78 \\
South (vs. Northeast) & $\mathbf{0 . 8 2}$ & 0.73 & 0.92 \\
West (vs. Northeast) & 1.12 & 0.99 & 1.27 \\
$>100 \%-199 \%$ FPL (vs. $\leq 100 \%$ FPL) & $\mathbf{1 . 9 1}$ & 1.67 & 2.19 \\
$\geq 200 \%$ FPL (vs. $\leq 100 \%$ FPL) & 2.27 & 1.99 & 2.58 \\
Unknown FPL (vs. $\leq 100 \%$ FPL) & $\mathbf{1 . 3 1}$ & 1.13 & 1.51 \\
\hline
\end{tabular}

NOTES: The logistic regression model: The model represented in the set of columns shows the OR for reporting this outcome among Medicare, Medicaid, and uninsured respondents compared to the reference group with private insurance. Age is continuous, so the corresponding OR is for a 1-year increase in age. The model includes additional covariates for geographic region and annual household income relative to the federal poverty level (FPL). All numbers in bold represent odds ratios that are statistically significant $(\mathrm{p}<0.05)$ at the $95 \%$ confidence level. SOURCE: Pew Research Center’s 2012 Health Survey (Internet \& American Life Project) telephone interviews.

\section{Medicaid beneficiaries more likely than the privately insured to share health information online}

\section{Online Information Sharing (ONLY \\ INTERNET USERS): Still thinking just about the last 12 months, have you posted a health-related question online or shared your own personal health experience online in any way?}

Only self-reported Internet users were asked to respond yes, no, don't know, or refused to the above question. Few respondents reported sharing information online (Exhibit 7), regardless of insurance type. The unadjusted percent of Medicaid beneficiaries (16\%) that shared information online was approximately double the $6-7 \%$ of Medicare beneficiaries, the uninsured, or the privately insured that reported similar behavior.

After adjustment (Exhibit 8), Medicare beneficiaries had odds of sharing information online comparable to the privately insured (unadjusted $\mathrm{OR}=0.81,95 \%$ CI: 0.67-0.98; adjusted $\mathrm{OR}=1.19,95 \% \mathrm{CI}$ : 0.94-1.49). Medicaid beneficiaries were more likely to share information online than were privately insured individuals before and after accounting for individual characteristics (Exhibit 8). 
Exhibit 6. mHealth Use Through Phone Applications, Among Subjects with a Cell Phone (Multivariate Logistic Model)

\begin{tabular}{|c|c|c|c|}
\hline & OR & $95 \%$ & CI \\
\hline Medicaid (vs. Private) & 0.53 & 0.42 & 0.67 \\
\hline Medicare (vs. Private) & 0.58 & 0.45 & 0.75 \\
\hline None (vs. Private) & 0.52 & 0.44 & 0.62 \\
\hline Age & 0.96 & 0.96 & 0.97 \\
\hline Female (vs. Male) & 1.33 & 1.20 & 1.49 \\
\hline College Degree (vs. No College Degree) & 1.51 & 1.35 & 1.70 \\
\hline Hispanic (vs. non-Hispanic) & 0.91 & 0.76 & 1.08 \\
\hline Black (vs. White) & 1.24 & 1.05 & 1.45 \\
\hline Other (vs. White) & 1.42 & 1.22 & 1.66 \\
\hline Fair/Poor health (vs. Not) & 0.92 & 0.77 & 1.10 \\
\hline Any Chronic Dx (vs. None) & 1.17 & 1.03 & 1.32 \\
\hline Any Emergency or Health Shock (vs. None) & 1.74 & 1.54 & 1.95 \\
\hline Active Caregiver (vs. Not a Caregiver) & 1.37 & 1.23 & 1.52 \\
\hline Internet user (vs. non-Internet user) & 3.58 & 2.40 & 5.34 \\
\hline Midwest (vs. Northeast) & 1.16 & 0.97 & 1.38 \\
\hline South (vs. Northeast) & 1.40 & 1.20 & 1.64 \\
\hline West (vs. Northeast) & 1.63 & 1.38 & 1.92 \\
\hline$>100 \%-199 \%$ FPL (vs. $\leq 100 \%$ FPL) & 1.85 & 1.52 & 2.26 \\
\hline$\geq 200 \%$ FPL (vs. $\leq 100 \%$ FPL) & 1.88 & 1.55 & 2.28 \\
\hline Unknown FPL (vs. $\leq 100 \%$ FPL) & 1.63 & 1.30 & 2.06 \\
\hline
\end{tabular}

NOTES: The logistic regression model: The model represented in the set of columns shows the OR for reporting this outcome among Medicare, Medicaid, and uninsured respondents compared to the reference group with private insurance.

Age is continuous, so the corresponding OR is for a 1-year increase in age. The model includes additional covariates for geographic region and annual household income relative to the federal poverty level (FPL). All numbers in bold represent odds ratios that are statistically significant $(\mathrm{p}<0.05)$ at the $95 \%$ confidence level.

SOURCE: Pew Research Center's 2012 Health Survey (Internet \& American Life Project) Telephone Interviews.

\section{Privately insured adults more likely than all others to use mHealth on their cell phones}

\author{
Self-Management mHealth Tools \\ (ALL CELL PHONE USERS): On \\ your cell phone, do you happen to \\ have any software applications or \\ "apps" that help you track or manage \\ your health, or not?
}

Only self-reported cell phone users were asked to respond yes, no, don't know, or refused to the above question. The majority of survey respondents had a cell phone and a landline phone. Over $75 \%$ of privately insured adults and slightly over $50 \%$ of each of the other insurance groups had a cell phone. More than half of adults from all insurance groups except for those on Medicare (20\%) accessed the Internet from a cell phone, tablet, or other mobile handheld device. More than $85 \%$ of cell phone users from all insurance types did not use mHealth applications on their cell phones (Exhibit 9). Among cell phone users, 15\% of 
Exhibit 7. Percent Sharing Health Information Online, by Insurance Type (Unadjusted Percent)

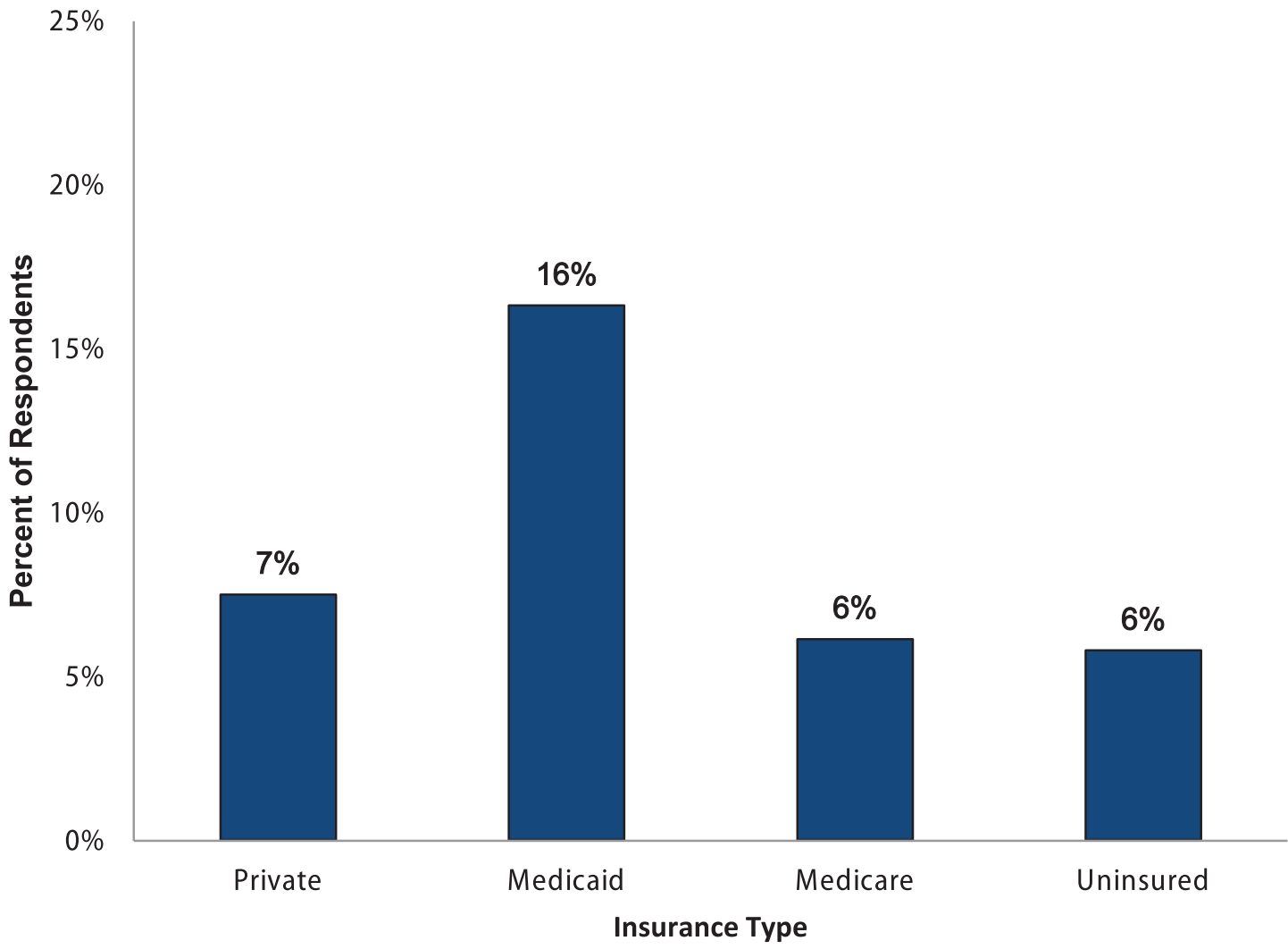

NOTES: Percents represent unadjusted values, weighted, using information from the 1999 CPS. Across all measures, $<1 \%$ responded "Don't know" or "Refused." Denominator consists of all subjects reporting having insurance of each type AND who reported being Internet users. When subjects report having both Medicare and Medicaid (i.e., dually eligible), we classified them as having Medicare.

SOURCE: Pew Research Center's 2012 Health Survey (Internet \& American Life Project) telephone interviews.

privately insured adults, five times as many Medicare beneficiaries (3\%), used health "apps" on their mobile devices. The unadjusted percent of privately insured adults using mHealth was almost double the share of Medicaid beneficiaries and the uninsured using health "apps" on their cell phones. The magnitude of these differences in mHealth use by insurance type decreased after adjustment (e.g., $\mathrm{OR}=0.58$ for Medicare vs. privately insured adults, 95\% CI: $0.45-0.75 ; \mathrm{OR}=0.53$ for Medicaid vs. privately insured adults, $95 \%$ CI: $0.42-0.67$; OR $=0.52$ for the uninsured vs. privately insured adults, $95 \%$ CI: 0.44-0.62, Exhibit 6).

\section{Medicare beneficiaries more likely than privately insured adults to text with health care professionals}

\section{Text Communication (ONLY CELL PHONE USERS WHO SEND/RE- \\ CEIVE TEXTS): Do you receive any TEXT updates or alerts about health or medical issues, such as from your doctors or pharmacists?}

Only self-reported cell phone users who send/ receive texts were asked to respond yes, no, don't know, or refused to the above question. Few respondents reported receiving text messages 
Exhibit 8. Sharing Health Information Online (Multivariate Logistic Model)

\begin{tabular}{llll}
\hline & OR & $95 \%$ & CI \\
\hline Medicaid (vs. Private) & 2.15 & 1.74 & 2.66 \\
Medicare (vs. Private) & 1.19 & 0.94 & 1.49 \\
None (vs. Private) & $\mathbf{0 . 8 1}$ & 0.66 & 1.00 \\
Age & $\mathbf{0 . 9 8}$ & 0.97 & 0.98 \\
Female (vs. Male) & $\mathbf{1 . 3 9}$ & 1.22 & 1.59 \\
College Degree (vs. No College Degree) & $\mathbf{1 . 7 0}$ & 1.48 & 1.95 \\
Hispanic (vs. non-Hispanic) & $\mathbf{1 . 5 7}$ & 1.30 & 1.89 \\
Black (vs. White) & $\mathbf{0 . 6 2}$ & 0.50 & 0.76 \\
Other (vs. White) & $\mathbf{0 . 5 3}$ & 0.43 & 0.65 \\
Fair/Poor health (vs. Not) & $\mathbf{0 . 8 1}$ & 0.68 & 0.97 \\
Any Chronic Dx (vs. None) & $\mathbf{1 . 7 5}$ & 1.51 & 2.02 \\
Any Emergency or Health Shock (vs. None) & $\mathbf{2 . 2 5}$ & 1.97 & 2.58 \\
Active Caregiver (vs. Not a Caregiver) & $\mathbf{1 . 6 3}$ & 1.43 & 1.85 \\
Midwest (vs. Northeast) & $\mathbf{1 . 3 7}$ & 1.11 & 1.69 \\
South (vs. Northeast) & $\mathbf{1 . 3 6}$ & 1.12 & 1.65 \\
West (vs. Northeast) & $\mathbf{1 . 7 4}$ & 1.43 & 2.12 \\
$>100 \%-199 \%$ FPL (vs. £100\% FPL) & $\mathbf{1 . 7 4}$ & 1.41 & 2.14 \\
${ }^{3}$ 200\% FPL (vs. £100\% FPL) & $\mathbf{1 . 3 1}$ & 1.06 & 1.63 \\
Unknown FPL (vs. $\leq 100 \%$ FPL) & 1.27 & 0.98 & 1.64 \\
\hline
\end{tabular}

NOTES: The logistic regression model: The model represented in the set of columns shows the OR for reporting this outcome among Medicare, Medicaid, and uninsured respondents compared to the reference group with private insurance. Age is continuous, so the corresponding OR is for a 1-year increase in age. The model includes additional covariates for geographic region and annual household income relative to the federal poverty level (FPL). All numbers in bold represent odds ratios that are statistically significant $(\mathrm{p}<0.05)$ at the $95 \%$ confidence level.

SOURCE: Pew Research Center's 2012 Health Survey (Internet \& American Life Project) telephone interviews.

from health professionals (Exhibit 10). More Medicare beneficiaries (23\%) reported receiving text messages than did privately insured adults. Before and after adjustment (Exhibit 11), Medicare beneficiaries were more likely to have received text updates or alerts about health or medical issues from doctors or pharmacists than respondents with private insurance coverage (unadjusted $\mathrm{OR}=3.10,95 \%$ CI: 2.64-3.63; adjusted $\mathrm{OR}=2.65$, 95\% CI: 2.18-3.23).

\section{Discussion}

We examined the use of the Internet and mHealth to obtain health information among adults who were privately insured, publicly insured (Medicare or Medicaid), or uninsured. Adults with different insurance coverage vary in their individual, family, and medical traits, as confirmed in the survey sample. We found substantial differences in Internet and mHealth use among adults in our insurance-based groups, which were strongly associated with differences in individual and clinical traits (for additional analysis, see Supplement, Exhibits A1-A6). After adjustment, we found fewer differences in use by insurance type (e.g., Medicare beneficiaries had similar odds of specific health information behaviors), and the direction of some associations changed (e.g., reversal in the association where Medicaid beneficiaries became more likely 


\section{Exhibit 9. Percent Reporting mHealth Usage through Cell Phone Applications, by Insurance Type (unadjusted percent)}

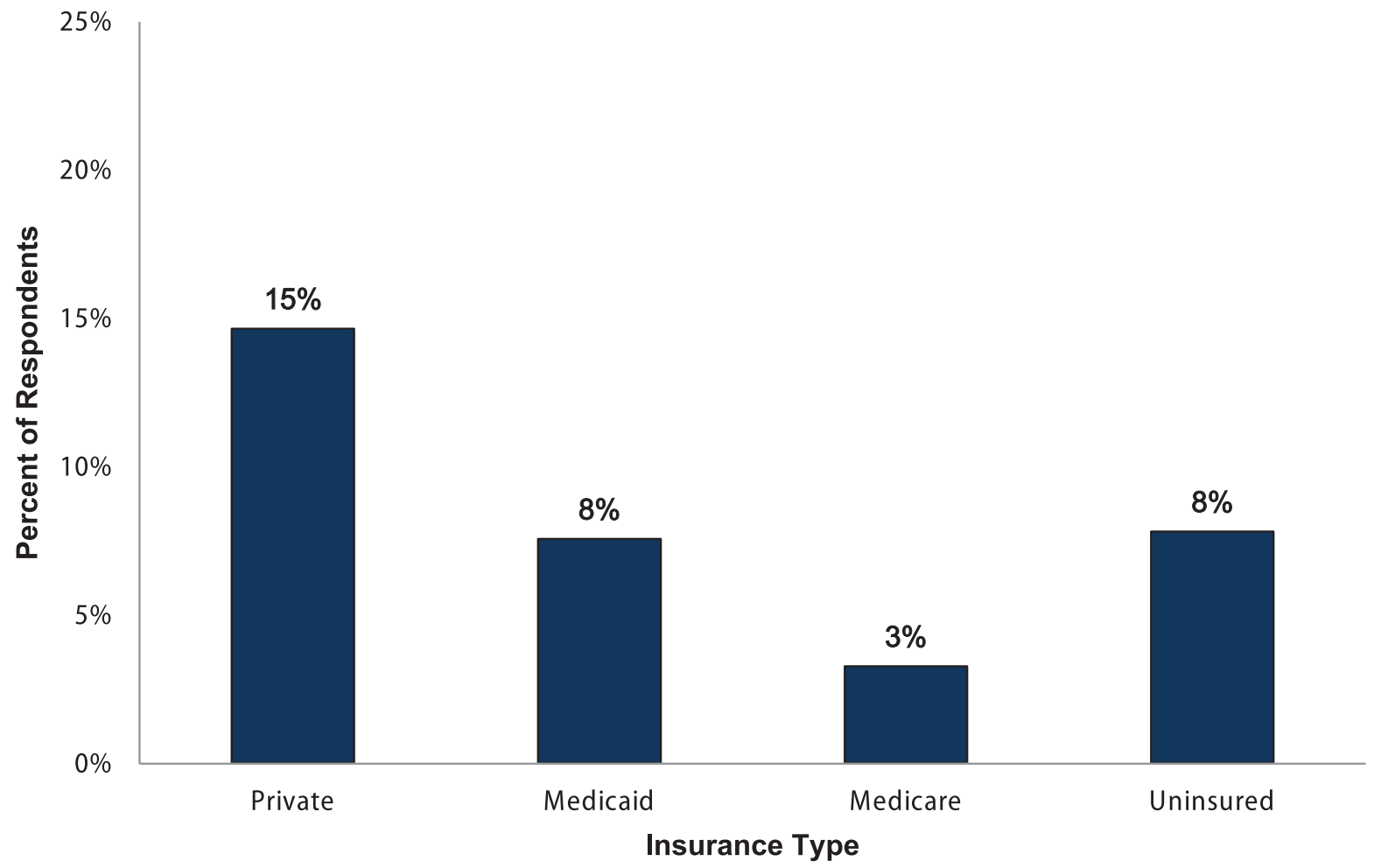

NOTES: Percents represent unadjusted values of mHealth use through cell phone apps, weighted, using information from the 1999 CPS. Across all measures, $<1 \%$ responded "Don't know" or "Refused." Denominator consists of all subjects reporting having insurance of each type AND who report having a cellular telephone. When subjects report having both Medicare and Medicaid (i.e., dually eligible) we classified them as having Medicare.

SOURCE: Pew Research Center's 2012 Health Survey (Internet \& American Life Project) telephone interviews.

to seek information online from a doctor than privately insured adults after adjustment).

Therefore, we found that insurance type alone does not explain the variation observed in eHealth. Though insurance might be an informative predictor of eHealth use, our results suggest that any evaluations of insurance type and technology use among population subgroups cannot ignore the variation due to individual socio-demographic factors. Policy interventions often target populations according to insurance coverage, but our results suggest that future policies to facilitate technology use targeted to insurance groups alone will not address all major contributing sources to technology use variation.
Our results showing that eHealth use remains limited despite access to the Internet and cell phones are consistent with the literature implying that access alone cannot explain differences in utilization by insurance type (Fung et al., 2006; Span, 2013). Our results also reiterate that even after accounting for insurance and income, disparities in access to technology-based care remain. These findings suggest that more investigations are needed to explain the digital divide with respect to eHealth. The Pew Research Center survey provides valuable, impartial information about how Americans use eHealth, and this study indicates how insurance type might be associated with that use. Consistent assessment of use will provide 


\section{Exhibit 10. Percent Reporting Texting with Health Professionals, by Insurance Type (Unadjusted Percent)}

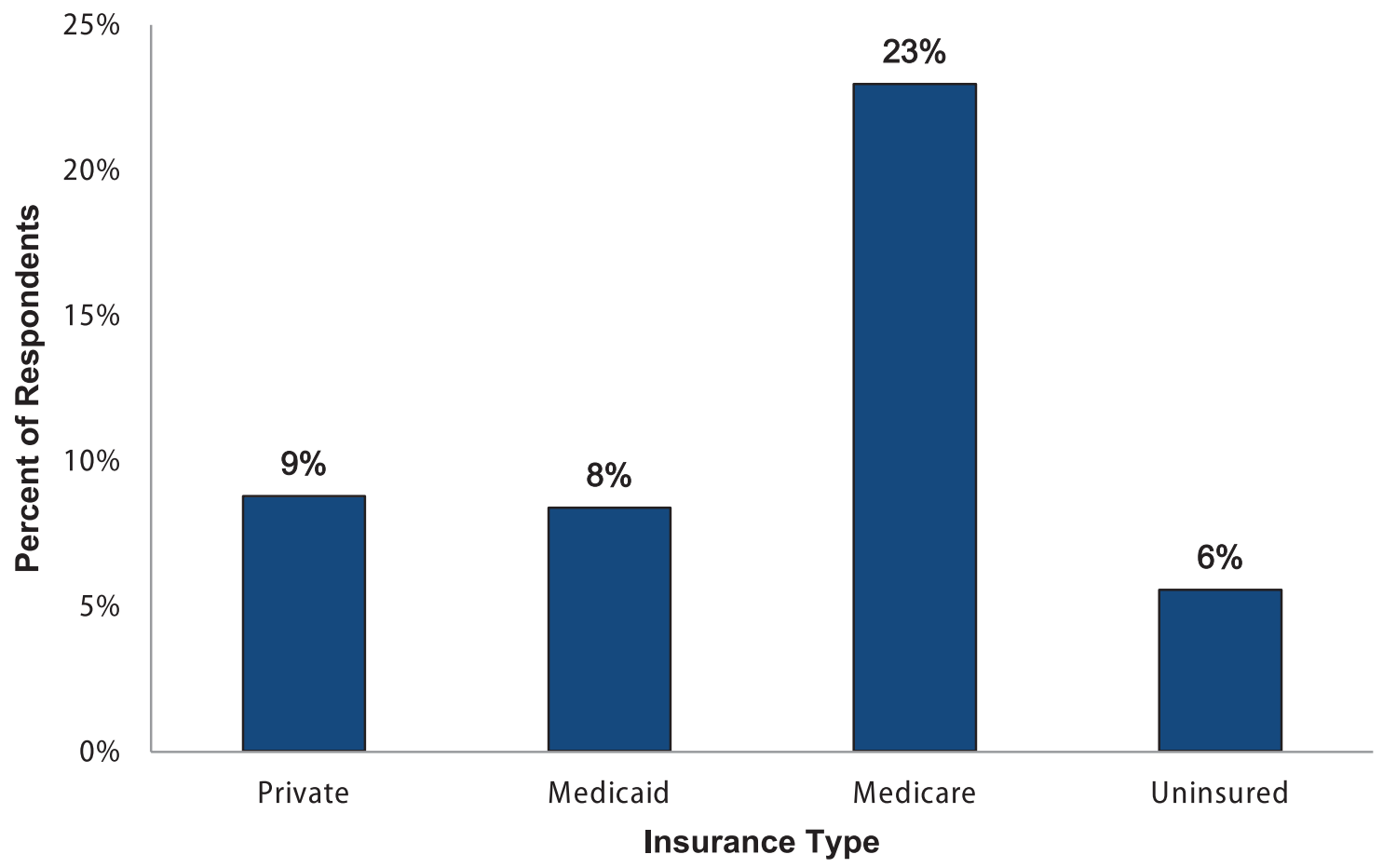

NOTES: Percents represent unadjusted values of respondent texting with health professionals, weighted, using information from the 1999 CPS. Across all measures, $<1 \%$ responded "Don't know" or "Refused." Denominator consists of all subjects reporting having insurance of each type AND who report having a cellular telephone. When subjects report having both Medicare and Medicaid (i.e., dually eligible) we classified them as having Medicare.

SOURCE: Pew Research Center's 2012 Health Survey (Internet \& American Life Project) telephone interviews.

knowledge on how to employ and target eHealth tools within the health care system.

The Pew data and this study have notable limitations. The survey results are based on selfreported behaviors, which are subject to recall bias and could be correlated with other traits (e.g., level of need). Due to our cross-sectional study design, our study is limited to a descriptive analysis representing associations rather than any causal inferences.

In conclusion, eHealth and mHealth tools represent promising technologies to promote health and potentially improve the efficiency of care delivery (e.g., provide comparable health at lower cost). These tools are in their early stages, with open questions concerning equity in access, frequency of use, and net impact. These interviews offer hints of first steps to bridge the technological divide, and, thus, improve medical care while lowering costs of health care delivery (DeBronkart, 2013; Jackson, 2013; Steinhubl, Muse, \& Topol, 2013).

\section{Disclaimer}

The authors have been requested to report any funding sources and other affiliations that may represent a conflict of interest. The statements contained in this manuscript are solely those of the authors and do not necessarily reflect the views or policies of neither the Centers for Medicare \& Medicaid Services nor the Department of Health and Human Services. The authors assume responsibility for the accuracy and completeness of the information contained in this manuscript.

\section{Correspondence}

Loren Saulsberry, B.A., Harvard University-Health Policy, 14 Story Street, Cambridge, MA 02138, lsaulsberry@fas.harvard.edu, Tel. 617-724-4744 
Exhibit 11. Texting with Health Care Professionals (Multivariate Logistic Model)

\begin{tabular}{|c|c|c|c|}
\hline & OR & $95 \%$ & CI \\
\hline Medicaid (vs. Private) & 0.79 & 0.61 & 1.02 \\
\hline Medicare (vs. Private) & 2.65 & 2.18 & 3.23 \\
\hline None (vs. Private) & 0.67 & 0.54 & 0.83 \\
\hline Age & 1.00 & 0.99 & 1.00 \\
\hline Female (vs. Male) & 1.63 & 1.44 & 1.86 \\
\hline College Degree (vs. No College Degree) & 1.42 & 1.24 & 1.63 \\
\hline Hispanic (vs. non-Hispanic) & 0.73 & 0.59 & 0.91 \\
\hline Black (vs. White) & 1.47 & 1.23 & 1.75 \\
\hline Other (vs. White) & 1.46 & 1.21 & 1.75 \\
\hline Fair/Poor health (vs. Not) & 0.93 & 0.78 & 1.12 \\
\hline Any Chronic Dx (vs. None) & 1.72 & 1.50 & 1.99 \\
\hline Any Emergency or Health Shock (vs. None) & 1.20 & 1.04 & 1.38 \\
\hline Active Caregiver (vs. Not a Caregiver) & 1.92 & 1.69 & 2.18 \\
\hline Internet user (vs. non-Internet user) & 0.67 & 0.53 & 0.85 \\
\hline Midwest (vs. Northeast) & 1.02 & 0.83 & 1.27 \\
\hline South (vs. Northeast) & 1.29 & 1.07 & 1.56 \\
\hline West (vs. Northeast) & 1.56 & 1.28 & 1.91 \\
\hline$>100 \%-199 \%$ FPL (vs. $\leq 100 \%$ FPL) & 1.44 & 1.17 & 1.77 \\
\hline$\geq 200 \%$ FPL (vs. $\leq 100 \%$ FPL) & 1.04 & 0.84 & 1.29 \\
\hline Unknown FPL (vs. $\leq 100 \%$ FPL) & 0.46 & 0.34 & 0.62 \\
\hline
\end{tabular}

NOTES: The logistic regression model: The model represented in the set of columns shows the OR for reporting this outcome among Medicare, Medicaid, and uninsured respondents compared to the reference group with private insurance. Age is continuous, so the corresponding OR is for a 1-year increase in age. The model includes additional covariates for geographic region and annual household income relative to the federal poverty level (FPL). All numbers in bold represent odds ratios that are statistically significant $(\mathrm{p}<0.05)$ at the $95 \%$ confidence level.

SOURCE: Pew Research Center’s 2012 Health Survey (Internet \& American Life Project) telephone interviews.

\section{References}

Beckjord, E. B., Finney Rutten, L. J., Squiers, L., Arora, N. K., Volckmann, L., Moser, R. P., \& Hesse, B. W. (2007). Use of Internet to Communicate with Health Care Providers in the United States; Estimates from the 2003 and 2005 Health Information National Trends Surveys (HINTS). Journal of Medical Internet Research, 9(3), e20. PubMed http://dx.doi.org/10.2196/jmir.9.3.e20

CMS (Centers for Medicare \& Medicaid Services) (2013). eHealth Programs. Retrieved from http://www.cms.gov/eHealth/programs.html
Cohen, R. A., \& Adams, P. F. (2011). Use of the Internet for Health Information: United States, 2009 (NCHS Data Brief No. 66). Hyattsville, MD: National Center for Health Statistics. Retrieved from http://www.cdc.gov/nchs/data/ databriefs/db66.htm

DeBronkart D. (2013). How the e-Patient Community Helped Save My Life: An Essay by Dave deBronkart. BMJ, 46, f1990. Retrieved from http://www.bmj.com/ content $/ 346 / \mathrm{bmj} . \mathrm{f} 1990$ ? tab $=$ response-form doi: 10.1136/bmj.f1990 
Fox, S., \& Jones, S. (2009). The Social Life of Health Information. Pew Research Center, Pew Internet \& American Life Project. Retrieved from http:// www.pewinternet.org/Reports/2009/8-TheSocial-Life-of-Health-Information.aspx

Fox, S. (2011). The Social Life of Health Information, 2011. Pew Research Center, Pew Internet \& American Life Project. Retrieved from http://www.pewinternet.org/files/oldmedia/Files/Reports/2011/PIP_Social_Life_ of_Health_Info.pdf

Fox, S. \& Duggan, M. (2013a, January 15). Health Online 2013. Pew Research Center, Pew Internet \& American Life Project. Retrieved from http:// www.pewinternet.org/2013/01/15/healthonline-2013-2/

Fox, S. \& Duggan, M. (2013b, January 28). Tracking for Health. Pew Research Center, Pew Internet \& American Life Project. Retrieved from http:// www.pewinternet.org/Reports/2013/Trackingfor-Health.aspx

Fung, V., Ortiz, E., Huang, J., Fireman, B., Miller, R., Selby, J. V., \& Hsu, J. (2006). Early Experiences with e-Health Services (1999-2002): Promise, Reality, and Implications. Medical Care, 44, 491-496. http://dx.doi.org/10.1097/01. mlr.0000207917.28988.dd PubMed

Ginsberg, J. (2011). Search to Rx: Cancer. The e-Patient's Path to Treatment. Google/Compete, U.S. Retrieved from http://ssl.gstatic.com/ think/docs/search-to-rx-cancer_researchstudies.pdf

Goel, M. S., Brown, T. L., Williams, A., HasnainWynia, R., Thompson, J. A., \& Baker, D. W. (2011). Disparities in Enrollment and Use of An Electronic Patient Portal. Journal of General Internal Medicine, 26(10), 1112-1116. Accessed
December 2013 http://dx.doi.org/10.1007/ s11606-011-1728-3 PubMed

Hsu, J., Huang, J., Kinsman, J., Fireman, B., Miller, R., Selby, J., \& Ortiz, E. (2005). Use of e-Health services between 1999 and 2002: A Growing Digital Divide. Journal of the American Medical Informatics Association, 12(2), 164-171. http:// dx.doi.org/10.1197/jamia.M1672 PubMed

Jackson, T. (2013). Patient Powered Health. [doi: ]. BMJ (Clinical Research Ed.), 346, f2255.

KCMU (Kaiser Commission on Medicaid and the Uninsured) (2013). The Uninsured: A Primer-Key Facts about Health Insurance on the Eve of Coverage Expansions. Kaiser Family Foundation. Retrieved from http://kff.org/ uninsured/report/the-uninsured-a-primer-keyfacts-about-health-insurance-on-the-eve-ofcoverage-expansions/

KFF (Kaiser Family Foundation) (2007). Key Facts: Race, Ethnicity \& Medical Care. Retrieved from http://kaiserfamilyfoundation.files.wordpress. com/2013/01/6069-02.pdf

KFF (Kaiser Family Foundation) (2008). Health Care and the 2008 Elections. Retrieved from http://kaiserfamilyfoundation.files.wordpress. com/2013/01/7830.pdf

Mead, H., Cartwright-Smith, L., Jones, K., Ramos, C., \& Siegel, B. (2008). Racial and Ethnic Disparities in U.S. Health Care: A Chartbook. The Commonwealth Fund. Retrieved from http:// www.commonwealthfund.org/usr_doc/mead_ racialethnicdisparities_chartbook_1111.pdf

ONC (The Office of the National Coordiantor for Health Information Technology) (2013a). Health IT Adoption Programs. Retrieved from http://www.healthit.gov/policy-researchersimplementers/health-it-adoption-programs 
ONC (The Office of the National Coordiantor for Health Information Technology) (2013b) Meaningful Use. Retrieved from http://www.healthit.gov/policy-researchersimplementers/meaningful-use-stage- 2

Pew Research Center (2012).September2012-Health Tracking (prelim). Pew Internet \& American Life Project. Retrieved from http://www.pewinternet. org/Shared-Content/Data-Sets/2012/September2012--Health-Tracking-(prelim).aspx

Span, P. (2013). Online Habits Coming Slowly to Older Adults. The New York Times, Retrieved from http://newoldage.blogs.nytimes. com/2013/04/08/online-habits-coming-slowlyto-older-adults/\#postComment
Steinhubl, S. R., Muse, E., \& Topol, E. (2013). Can Mobile Health Technologies Transform Health Care? Journal of the American Medical Association. http://dx.doi.org/10.1001/ jama.2013.281078 PubMed

U.S.CensusBureau.(2009,March).CurrentPopulation Survey (CPS), 1999: Annual Demographic File. Retrieved from http://www.census.gov/

White, R. W., Tatonetti, N. P., Shah, N. H., Altman, R. B., \& Horvitz, E. (2011). Web-Scale Pharmacovigilance: Listening to Signals from the Crowd. Brief Communication Journal of the American Medical Informatics Association. Retrieved from http://jamia.bmj.com/content/ early/2013/02/05/amiajnl-2012-001482.abstract 


\section{SUPPLEMENT}

This supplement includes analysis of additional Pew survey questions on health information seeking behavior. For each survey question, the question text is presented specifying which respondents the question was directed to. Unadjusted responses are presented in a figure immediately following each survey question. Finally, adjusted logistic regression results are included in tabular format.

\section{Advice from Friends and Family} Question Asked of ALL RESPONDENTS: Thinking about the LAST time you had a serious health issue or experienced any significant change in your physical health... Did you get information, care, or support from friends or family?

Advice from Others with Comparable Conditions Question Asked of ALL RESPONDENTS: Thinking about the LAST time you had a serious health issue or experienced any significant change in your physical health...Did you get information, care or support from others who have the same health condition?

\section{Exhibit A1. Percent Seeking Health Information from Friends and Family, Any Online Efforts vs. Offline Only, by Insurance Type (Unadjusted Percent)}

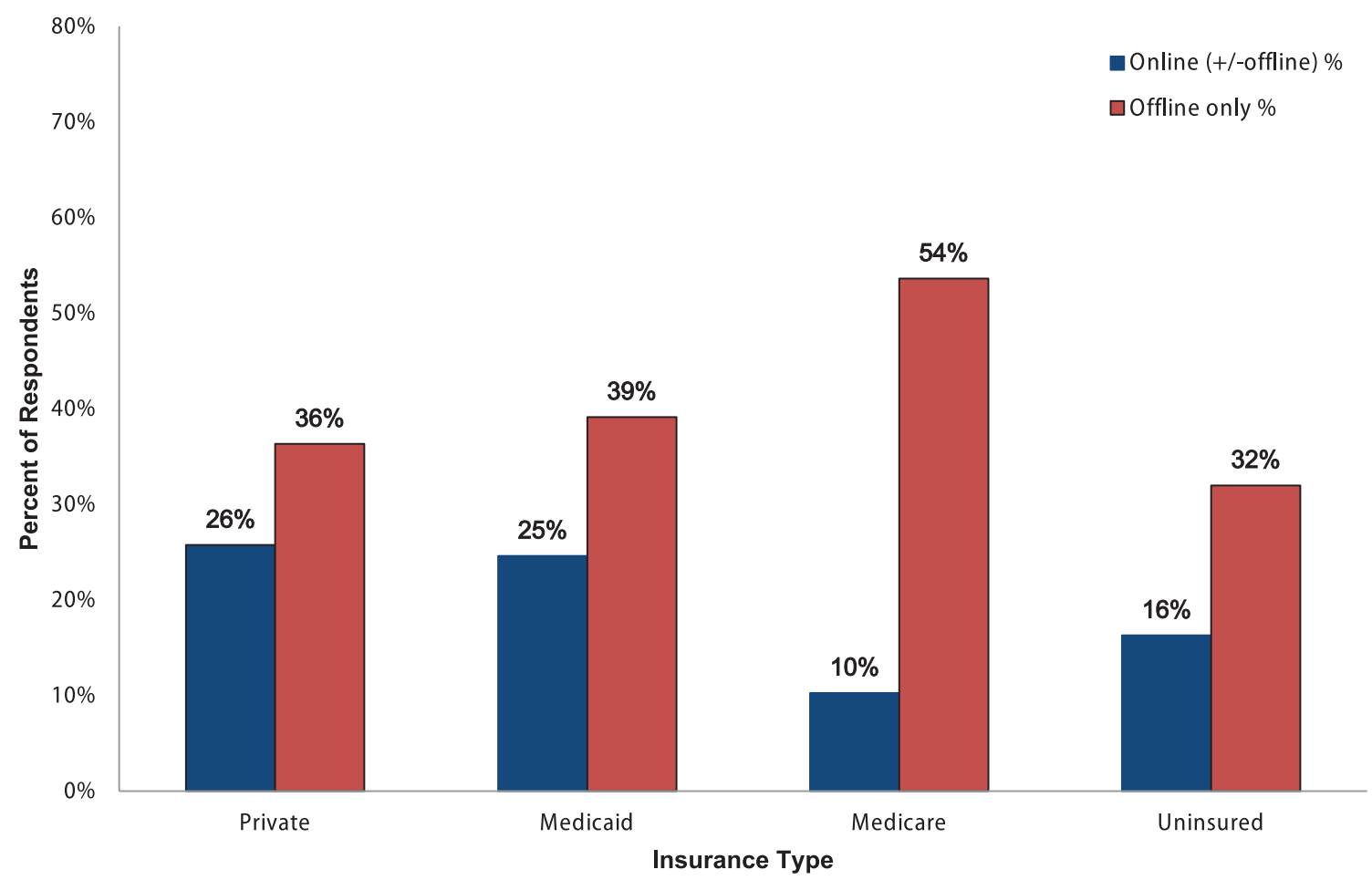

NOTES: Percents represent unadjusted values weighted using information from the 1999 CPS. Percents do not total 100 as all responses in Other were excluded from Exhibit 4. Other included “No, did not use this source," “Don't know," and "Refused.” Across all measures, <3\% (weighted) responded "Don't know," or "Refused.” Denominator consists of all respondents including subjects reporting having each type of insurance. When subjects report having both Medicare and Medicaid (i.e., dually eligible), we classified them as having Medicare. SOURCE: Pew Research Center's 2012 Health Survey (Internet \& American Life Project) telephone interviews. 
Internet Self-Diagnosis Question Asked

of ALL INTERNET USERS: Have

you ever gone online specifically to try to figure out what medical condition you or someone else might have?

Exhibit A2. Seeking Information from Friends and Family Through the Internet (Multivariate Logistic Model)

\begin{tabular}{llll}
\hline & OR & $95 \%$ & CI \\
\hline Medicaid (vs. Private) & $\mathbf{1 . 4 1}$ & 1.21 & 1.63 \\
Medicare (vs. Private) & 1.12 & 0.97 & 1.29 \\
None (vs. Private) & $\mathbf{0 . 8 6}$ & 0.76 & 0.97 \\
Age & $\mathbf{0 . 9 7}$ & 0.96 & 0.97 \\
Female (vs. Male) & $\mathbf{1 . 4 0}$ & 1.29 & 1.51 \\
College Degree (vs. No College Degree) & $\mathbf{1 . 8 4}$ & 1.70 & 2.01 \\
Hispanic (vs. non-Hispanic) & 0.90 & 0.80 & 1.02 \\
Black (vs. White) & $\mathbf{0 . 6 6}$ & 0.58 & 0.75 \\
Other (vs. White) & 1.01 & 0.90 & 1.14 \\
Fair/Poor health (vs. Not) & $\mathbf{0 . 7 4}$ & 0.65 & 0.83 \\
Any Chronic Dx (vs. None) & 1.07 & 0.97 & 1.17 \\
Any Emergency or Health Shock (vs. None) & $\mathbf{1 . 6 7}$ & 1.53 & 1.83 \\
Active Caregiver (vs. Not a Caregiver) & 2.12 & 1.96 & 2.29 \\
Midwest (vs. Northeast) & $\mathbf{1 . 1 9}$ & 1.05 & 1.34 \\
South (vs. Northeast) & 0.92 & 0.83 & 1.03 \\
West (vs. Northeast) & $\mathbf{1 . 1 8}$ & 1.05 & 1.33 \\
$>100 \%-199 \%$ FPL (vs. $\leq 100 \%$ FPL) & $\mathbf{1 . 3 5}$ & 1.18 & 1.55 \\
$\geq 200 \%$ FPL (vs. $\leq 100 \%$ FPL) & 2.06 & 1.80 & 2.35 \\
Unknown FPL (vs. $\leq 100 \%$ FPL) & $\mathbf{0 . 7 7}$ & 0.65 & 0.91 \\
\hline NOI & &
\end{tabular}

NOTES: The logistic regression model: The model represented in the set of columns shows the OR for reporting this outcome among Medicare, Medicaid, and uninsured respondents compared to the reference group with private insurance. Age is continuous, so the corresponding OR is for a 1-year increase in age. The model includes additional covariates for geographic region and annual household income relative to the federal poverty level (FPL). All numbers in bold represent odds ratios that are statistically significant $(\mathrm{p}<0.05)$ at the $95 \%$ confidence level. SOURCE: Pew Research Center's 2012 Health Survey (Internet \& American Life Project) telephone interviews. 
Exhibit A3. Percent Seeking Health Information from Others with the Same Medical Condition, Any Online Efforts vs. Offline Only, by Insurance Type (Unadjusted Percent)

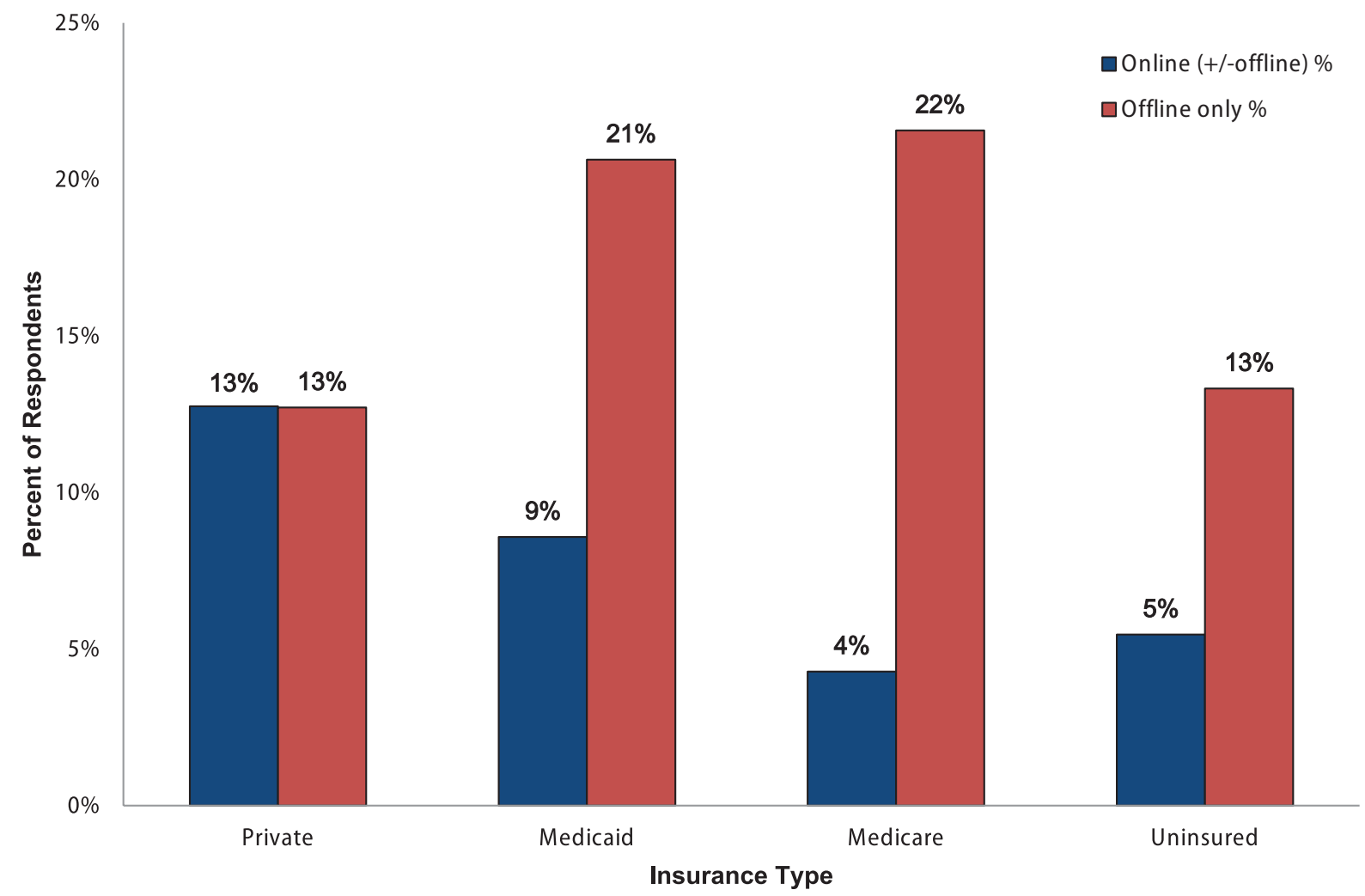

NOTES: Percents represent unadjusted values weighted using information from the 1999 CPS. Percents do not total 100 as all responses in Other were excluded from Exhibit 7. Other included “No, did not use this source," "Don’t know," and "Refused." Across all measures, $<3 \%$ (weighted) responded "Don't know," or "Refused." Denominator consists of all respondents including subjects reporting having each type of insurance. When subjects report having both Medicare and Medicaid (i.e., dually eligible), we classified them as having Medicare. SOURCE: Pew Research Center’s 2012 Health Survey (Internet \& American Life Project) telephone interviews. 
Exhibit A4. Seeking Information Online from Others with the Same Medical Condition (Multivariate Logistic Model)

\begin{tabular}{llll}
\hline & OR & $\mathbf{9 5 \%}$ & CI \\
\hline Medicaid (vs. Private) & 0.99 & 0.79 & 1.22 \\
Medicare (vs. Private) & 0.99 & 0.81 & 1.21 \\
None (vs. Private) & $\mathbf{0 . 6 1}$ & 0.50 & 0.73 \\
Age & $\mathbf{0 . 9 6}$ & 0.96 & 0.97 \\
Female (vs. Male) & $\mathbf{1 . 5 4}$ & 1.38 & 1.71 \\
College Degree (vs. No College Degree) & $\mathbf{1 . 5 6}$ & 1.39 & 1.75 \\
Hispanic (vs. non-Hispanic) & $\mathbf{0 . 6 3}$ & 0.52 & 0.76 \\
Black (vs. White) & 1.08 & 0.92 & 1.26 \\
Other (vs. White) & 0.88 & 0.74 & 1.05 \\
Fair/Poor health (vs. Not) & $\mathbf{0 . 6 4}$ & 0.54 & 0.76 \\
Any Chronic Dx (vs. None) & $\mathbf{1 . 1 3}$ & 1.00 & 1.28 \\
Any Emergency or Health Shock (vs. None) & $\mathbf{2 . 2 4}$ & 2.00 & 2.51 \\
Active Caregiver (vs. Not a Caregiver) & $\mathbf{1 . 4 6}$ & 1.31 & 1.62 \\
Midwest (vs. Northeast) & 0.92 & 0.78 & 1.09 \\
South (vs. Northeast) & 0.99 & 0.85 & 1.14 \\
West (vs. Northeast) & 1.15 & 0.99 & 1.35 \\
$>100 \%-199 \%$ FPL (vs. $\leq 100 \%$ FPL) & $\mathbf{1 . 5 9}$ & 1.30 & 1.94 \\
$\geq 200 \%$ FPL (vs. $\leq 100 \%$ FPL) & 2.71 & 2.23 & 3.29 \\
Unknown FPL (vs. $\leq 100 \%$ FPL) & 1.15 & 0.90 & 1.47 \\
\hline
\end{tabular}

NOTES: The logistic regression model: The model represented in the set of columns shows the OR for reporting this outcome among Medicare, Medicaid, and uninsured respondents compared to the reference group with private insurance. Age is continuous, so the corresponding OR is for a 1-year increase in age. The model includes additional covariates for geographic region and annual household income relative to the federal poverty level (FPL). All numbers in bold represent odds ratios that are statistically significant $(\mathrm{p}<0.05)$ at the $95 \%$ confidence level. SOURCE: Pew Research Center's 2012 Health Survey (Internet \& American Life Project) telephone interviews. 
Exhibit A5. Percent Attempting a Self-Diagnosis Through the Internet, by Insurance Type (Unadjusted Percent)

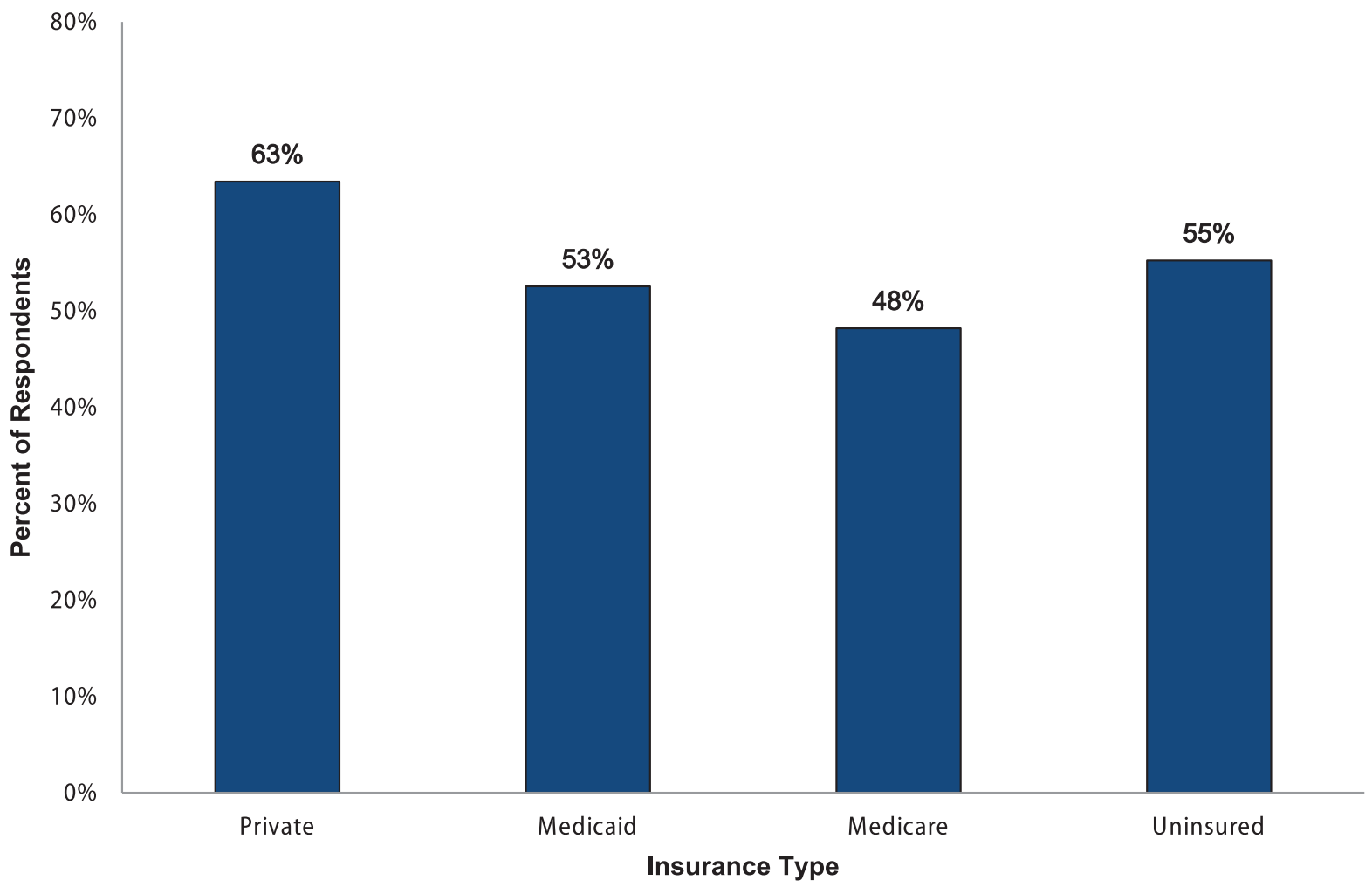

NOTES: Percents represent unadjusted values of online use for any of the listed reasons in the survey, weighted, using information from the 1999 CPS. Across all measures, $<1 \%$ responded "Don't know" or "Refused." Denominator consists of all subjects reporting having insurance of each type AND who report being Internet users. When subjects report having both Medicare and Medicaid (i.e., dually eligible) we classified them as having Medicare.

SOURCE: Pew Research Center's 2012 Health Survey (Internet \& American Life Project) telephone interviews. 
Exhibit A6. Attempt at Self-Diagnosis Through Online Search (Multivariate Logistic Model)

\begin{tabular}{llll}
\hline & OR & 95\% & CI \\
\hline Medicaid (vs. Private) & $\mathbf{0 . 6 3}$ & 0.53 & 0.74 \\
Medicare (vs. Private) & 0.87 & 0.76 & 1.00 \\
None (vs. Private) & $\mathbf{0 . 7 2}$ & 0.63 & 0.82 \\
Age & $\mathbf{0 . 9 7}$ & 0.97 & 0.98 \\
Female (vs. Male) & $\mathbf{1 . 3 3}$ & 1.22 & 1.44 \\
College Degree (vs. No College Degree) & $\mathbf{1 . 3 4}$ & 1.23 & 1.46 \\
Hispanic (vs. non-Hispanic) & $\mathbf{0 . 7 2}$ & 0.63 & 0.82 \\
Black (vs. White) & $\mathbf{0 . 8 5}$ & 0.75 & 0.97 \\
Other (vs. White) & $\mathbf{0 . 7 7}$ & 0.68 & 0.87 \\
Fair/Poor health (vs. Not) & $\mathbf{1 . 1 8}$ & 1.04 & 1.33 \\
Any Chronic Dx (vs. None) & $\mathbf{1 . 1 7}$ & 1.06 & 1.28 \\
Any Emergency or Health Shock (vs. None) & $\mathbf{1 . 1 8}$ & 1.08 & 1.29 \\
Active Caregiver (vs. Not a Caregiver) & $\mathbf{1 . 4 0}$ & 1.29 & 1.52 \\
Midwest (vs. Northeast) & $\mathbf{1 . 1 3}$ & 1.00 & 1.28 \\
South (vs. Northeast) & 1.01 & 0.90 & 1.13 \\
West (vs. Northeast) & $\mathbf{1 . 1 4}$ & 1.01 & 1.28 \\
$>100 \%-199 \%$ FPL (vs. $\leq 100 \%$ FPL) & $\mathbf{1 . 6 1}$ & 1.39 & 1.86 \\
$\geq 200 \%$ FPL (vs. $\leq 100 \%$ FPL) & $\mathbf{1 . 4 1}$ & 1.22 & 1.62 \\
Unknown FPL (vs. $\leq 100 \%$ FPL) & $\mathbf{1 . 2 7}$ & 1.08 & 1.51 \\
\hline
\end{tabular}

NOTES: The logistic regression model: The model represented in the set of columns shows the OR for reporting this outcome among Medicare, Medicaid, and uninsured respondents compared to the reference group with private insurance. Age is continuous, so the corresponding OR is for a 1-year increase in age. The model includes additional covariates for geographic region and annual household income relative to the federal poverty level (FPL). All numbers in bold represent odds ratios that are statistically significant $(\mathrm{p}<0.05)$ at the $95 \%$ confidence level. SOURCE: Pew Research Center's 2012 Health Survey (Internet \& American Life Project) telephone interviews. 